\title{
Using political science to progress public health nutrition: a systematic review
}

\author{
Katherine Cullerton ${ }^{1, *}$, Timothy Donnet ${ }^{2}$, Amanda Lee $^{3}$ and Danielle Gallegos ${ }^{1}$ \\ ${ }^{1}$ School of Exercise and Nutrition Sciences, Queensland University of Technology, Victoria Park Road, Kelvin Grove, \\ QLD 4059, Australia: ${ }^{2}$ School of Management, Queensland University of Technology, Brisbane, Queensland, \\ Australia: ${ }^{3}$ School of Public Health and Social Work, Queensland University of Technology, Kelvin Grove, \\ Queensland, Australia
}

Submitted 8 June 2015: Final revision received 29 July 2015: Accepted 19 August 2015: First published online 7 October 2015

\begin{abstract}
Objective: Poor dietary intake is the most important behavioural risk factor affecting health globally. Despite this, there has been little investment in public health nutrition policy actions. Policy process theories from the field of political science can aid understanding why policy decisions have occurred and identify how to influence ongoing or future initiatives. The present review aims to examine public health nutrition policy literature and identify whether a policy process theory has been used to analyse the process.

Design: Electronic databases were searched systematically for studies examining policy making in public health nutrition in high-income, democratic countries.

Setting: International, national, state and local government jurisdictions within high-income, democratic countries.

Subjects: Individuals and organisations involved in the nutrition policy-making process.

Results: Sixty-three studies met the eligibility criteria, most were conducted in the USA and a majority focused on obesity. The analysis demonstrates an accelerating trend in the number of nutrition policy papers published annually and an increase in the diversity of nutrition topics examined. The use of policy process theory was observed from 2003; however, it was utilised by only $14 \%$ of the reviewed papers. Conclusions: There is limited research into the nutrition policy process in highincome countries. While there has been a small increase in the use of policy process theory from 2003, an opportunity to expand its use is evident. We suggest that nutrition policy making would benefit from a pragmatic approach that ensures those trying to influence or understand the policy-making process are equipped with basic knowledge around these theories.
\end{abstract}

Keywords Nutrition policy Political theory Advocacy
Poor dietary intake is the single most important preventable behavioural risk factor affecting health globally ${ }^{(1)}$. In highincome countries the burden of disease due to poor dietary intake is at least $14 \%$ of the total disease burden, which is about double that due to cigarette smoking ${ }^{(1,2)}$. There is evidence that a range of nutrition strategies can effectively reduce diet-related disease, including individual-focused 'downstream' approaches and more 'upstream' population-based approaches. Downstream interventions often focus on adverse health behaviours through direct dietary interventions and require active participation by individuals ${ }^{(3)}$; upstream interventions focus on the wider circumstances that produce the adverse health behaviours. Intervening on the wider circumstances can be achieved through implementing policies that improve the social or physical food environment; for example, improving the availability and quality of healthy food choices, decreasing the cost of healthy food choices or changing the socio-cultural norms around food through public awareness campaigns ${ }^{(4)}$. Regulatory actions from governments combined with joint efforts from industry and society are often required to implement these policies in order to create healthier food systems ${ }^{(5)}$. There is increasing evidence that upstream population approaches 
are more cost-effective and can provide larger savings to the health-care system than downstream individual approaches ${ }^{(6-8)}$. However, despite this, there has been limited progress towards public policy action in many countries $^{(9,10)}$.

Public policy is defined as 'a program of action (or inaction) of a government to achieve specific goals ${ }^{(11)}$; it is the bedrock of the political process and is essential in directing investment ${ }^{(12)}$. Public policy making is rarely a linear process and is informed by interactions between institutions, politicians, advisers, interest groups, the public service plus a range of other participants ${ }^{(13)}$. Current public policy to address nutrition issues in high-income, democratic countries is inconsistent ${ }^{(10,14)}$. Numerous hypotheses have been given for this inconsistency including the power of vested interests, a lack of evidence and that tackling nutrition issues is too expensive and complex ${ }^{(10,14,15)}$. To understand why nutrition is not addressed more fully in public policy, the policy process needs to be better elucidated in terms of how it is influenced and by whom. This does not mean a focus on the technical content and design of policies; rather it is the analysis of specific aspects of the policy process. These include how ideas, knowledge, interests, power and institutions influence the policy decision-making process $^{(16)}$. In analysing the policy process, stakeholders may be able to use the findings to more effectively leverage for policy change.

Any discussion of the policy-making process needs to consider the nature of power. Power can be defined as control over outcomes, and this can occur through control over resources and/or control over actors ${ }^{(17)}$. The role of power in policy making has been explored by political scientists since the 1950s, with Lasswell and Kaplan noting 'the political process is the shaping, distribution, and exercise of power ${ }^{(18)}$. Public policies, it is argued, reflect the values of those with the greatest influence and are imbued with how those groups perceive the world to be, or ought to be ${ }^{(19)}$. Some believe that health policy making, like policy in other sectors, rests on the accumulation and use of power by those involved in the policy-making process $^{(20)}$. One way to increase one's power in the policy-making process is through effective advocacy. Advocacy is defined as 'active interventions by organisations on behalf of the collective interests they represent, that has the explicit goal of influencing public policy or the decisions of any institutional elite $e^{(21)}$.

Advocating for food and nutrition policy and government support to protect and promote health has been identified internationally as a core function for the public health nutrition workforce ${ }^{(22)}$. However, research has shown that the current workforce is largely disengaged from the advocacy component of the policy-making process and is unprepared for this type of work ${ }^{(23)}$. Nutrition practitioners and researchers often embrace policy advocacy with the belief that a scientific approach is all that is required; that is, providing high-level scientific evidence is enough to influence policy decisions. However, expecting a linear connection between scientific results and policy making reveals a misunderstanding of the political nature of policy environments ${ }^{(24,25)}$. While evidence is an important ingredient, it is only one component in the inherently political policy-making process. Assuming that policy making is a linear, rational process ignores the broader influences of political ideologies, institutions and powerful vested interests in shaping and selecting the 'knowledge' provided in the formulation of public policy ${ }^{(26,27)}$. By relying solely on scientific evidence as a platform for policy change and not acknowledging or understanding the political dimension of policy making, public health nutrition practitioners and researchers are unlikely to fully appreciate why desired policy outcomes fail to emerge and therefore why nutrition is often not addressed at a broad population level beyond the individual.

Conversely, the systematic study of the policy-making process has occurred in the field of political science since the 1950s, where many theories have been developed to explain the various components, including politics, process and power ${ }^{(28)}$. Applying political science policy process theories (PPT) retrospectively allows a greater understanding of why particular policy decisions were made, which can help advocates understand the complexities of the policy-making process as well as identify key actors and leverage points for power and influence in the process. An understanding of PPT can also aid in predicting the outcomes of ongoing or future initiatives ${ }^{(29,30)}$. Three commonly used PPT that have been validated empirically in multiple countries to explain and predict the policy-making process include the Advocacy Coalition Framework ${ }^{(31)}$, the Punctuated-Equilibrium Theory $^{(32)}$ and the Multiples Streams Theory ${ }^{(33)}$ (see Table 1 for a summary) ${ }^{(28)}$. These PPT have different components; they are, however, all theories of policy change which focus on agenda setting and policy adoption. Despite this raft of knowledge, very few public health experts utilise these empirically based PPT when analysing or trying to influence the policy-making process or the content of policies ${ }^{(34-36)}$. Publications in the public health policy area tend to focus on describing policy content and evaluating policy impact and outcomes, paying little attention to the policy-making process ${ }^{(26,37,38)}$.

A review of peer-reviewed papers reporting on policy process or content in 2010 found only $18 \%$ applied a $\mathrm{PPT}^{(34)}$. A systematic literature review of the health policy literature in low- and middle-income countries between 1994 and 2007 found that health policy analysis was in its infancy with the majority of studies being descriptive and very few utilising $\mathrm{PPT}^{(36)}$. While these reviews have been conducted across health promotion and public health generally, to date, no systematic review of public health nutrition policy papers has been undertaken. 
Table 1 Summary of influential theories of the policy-making process

\begin{tabular}{|c|c|c|c|}
\hline & Advocacy Coalition Framework & Multiple Streams Theory & Punctuated-Equilibrium Theory \\
\hline Summary & $\begin{array}{l}\text { Policy making is characterised by } \\
\text { the interaction of advocacy } \\
\text { coalitions within a policy } \\
\text { subsystem }\end{array}$ & $\begin{array}{l}\text { Policy making is composed of } \\
\text { three streams: problem; policy; } \\
\text { politics. These streams come } \\
\text { together during windows of } \\
\text { opportunity to cause major } \\
\text { policy change }\end{array}$ & $\begin{array}{l}\text { Policy making is characterised by } \\
\text { long periods of incremental } \\
\text { change punctuated by brief } \\
\text { periods of major policy change }\end{array}$ \\
\hline Individual motivation & $\begin{array}{l}\text { Belief system guides choices and } \\
\text { actions }\end{array}$ & $\begin{array}{l}\text { Assesses options until an } \\
\text { acceptable solution is found }\end{array}$ & $\begin{array}{l}\text { Salience of an issue depends on } \\
\text { context }\end{array}$ \\
\hline Drivers of policy change & $\begin{array}{l}\text { Alignment and activity of } \\
\text { coalitions. Outside factors can } \\
\text { realign beliefs and generate } \\
\text { change }\end{array}$ & $\begin{array}{l}\text { Opening of policy windows } \\
\text { capitalised on by policy } \\
\text { entrepreneurs }\end{array}$ & $\begin{array}{l}\text { Policy image and public } \\
\text { mobilisation can establish a new } \\
\text { policy monopoly. Entrepreneurs } \\
\text { and interest groups play a role }\end{array}$ \\
\hline
\end{tabular}

While reviews of health promotion and public health literature can provide general insights, public health nutrition policy is a particularly unique field. Unlike cigarettes or pathogens, the healthfulness of particular foods can be open to individual interpretation. Adding to this, choosing food is a necessary, but complex process. This complexity is due to food choices being deeply embedded in culture and influenced by many factors internal and external to the person, including biological, social, psychological, economic and environmental ${ }^{(39-42)}$. Macro-level environmental factors, including social norms, economic price structures, food marketing, agricultural policies, and food production and distribution, play an indirect role but have a substantial and powerful effect on what people eat ${ }^{(43)}$. Successfully impacting on these factors will often require a structural or political response. The complexity of the issue is further exacerbated by the many different voices of interest groups. These include not only those with obvious vested (social or financial) interests such as public health groups and food industry groups, but also 'alternative' health practitioners as well as celebrities and even actors advocating dietary recommendations. To advance our understanding of the unique field of public health nutrition policy, we conducted a systematic review of peer-reviewed literature to determine whether PPT is utilised to guide analysis in the literature.

\section{Methods}

The systematic review was conducted based on the PRISMA (Preferred Reporting Items for Systematic Reviews and Meta-Analyses) statement and a review protocol used by Breton and De Leeuw ${ }^{(34)}$ that examined the use of PPT in health promotion, refined to focus on food and nutrition policy. This review included English-language nutrition policy literature published between 1986 and December 2014 (Fig. 1). The start date was chosen as this was the year the Ottawa Charter ${ }^{(44)}$, which recommended a focus on healthy public policy as an effective strategy of health promotion, was released.
Five electronic databases (PubMed, Informit, CINAHL, PsycINFO and Scopus) were searched using the following keywords: '(politic* OR advoc* OR coalition OR influenc*) AND (nutri* OR food OR obesity) AND (polic*) AND (government)'. To limit settings-based approaches, on the two occasions when more than 500 papers were retrieved from a search, the terms 'AND NOT agriculture*' were included. Reference lists of relevant articles were also searched for eligible papers. Multiple papers referring to the same study contributed only once to the review.

The studies from the initial search ( $n$ 1932) were reviewed against the inclusion criteria (see Table 2). Papers were excluded if they were not primarily concerned with the food or nutrition policy-making process or policy content. In addition, papers were excluded if they recommended developing a new policy but provided no detail on how that should occur or if they only examined the views of the community about general policy directions. The application of the criteria resulted in 147 eligible papers.

All 147 papers were fully read by the first author and assessed as to whether insights from any empirically tested PPT had guided the policy research or theoretical reflections they reported, consistent with the method in Breton and De Leeuw ${ }^{(34)}$. When there was uncertainty as to whether a paper fit the inclusion criteria, it was reviewed by a second independent reviewer. Disagreements between reviewers were resolved by discussion until consensus was reached. A second screening was undertaken to exclude all papers concerning low-income and/or partial or non-democratic countries as defined by the Democracy Index 2014 ( $n$ 19), as it was felt these settings were too different from the health policy environments and systems of government of prime interest/relevance in the present study ${ }^{(45)}$.

The content of papers was scanned for topic areas, year of publication, use of PPT, country of focus and level of government, then results were tallied and depicted graphically (Microsoft ${ }^{\circledR}$ Excel version 2010). A data visualisation technique known as ebb-and-flow analysis 


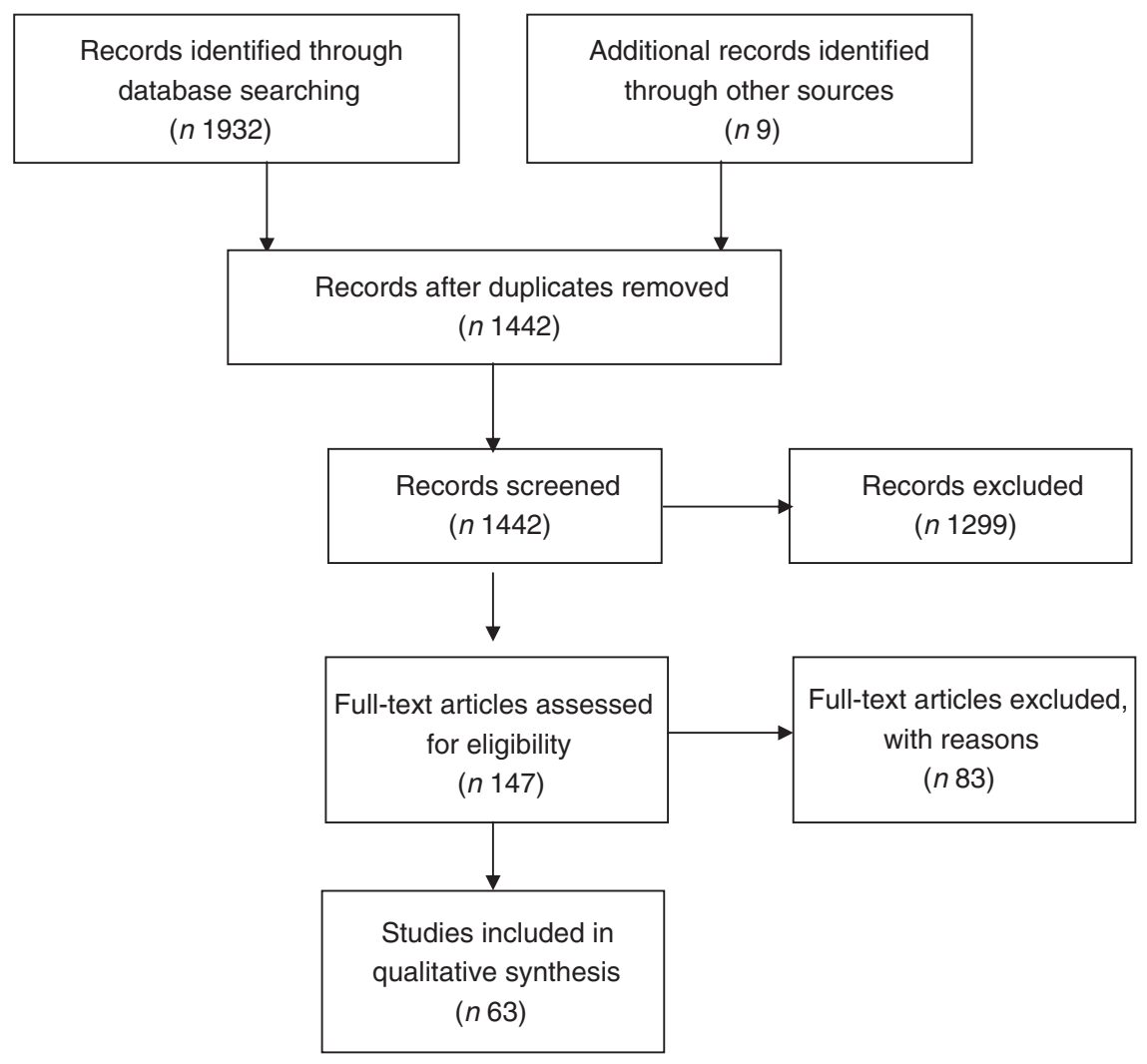

Fig. 1 PRISMA 2009 flow diagram

Table 2 Inclusion and exclusion criteria for the identification of journal articles reporting on policy research

Inclusion criteria

The article:

- Is in a peer-reviewed journal indexed in PubMed, Scopus, Informit, CINAHL or PsycINFO.

- Is in English.

- Was published between January 1986 and December 2014.

- Features in its abstract, title or subject headings the search terms: '(politic* OR advoc* OR coalition OR influenc ${ }^{\star}$ ) AND (nutri* OR food OR obesity) AND (polic*) AND (government)'. When more than 500 papers were retrieved from a search, the terms 'AND NOT agriculture*' were included.

- Reports on issues at the supra-national, national, state or local government level related to:

- The content or nature of a policy, i.e. (foreseen) components, effectiveness, impact, evolution.

- The policy change process, i.e. advocacy intervention or strategy, capacity building for advocacy, evidence and knowledge shaping in policy making, theoretical and methodological issues in policy analysis. Address a policy or policy process that goes beyond the walls of a specific workplace, school or other organisational setting.

Exclusion criteria

The article refers to:

- Policies related to a specific setting, e.g. workplace, school or other organisational setting.

- Policies related to clinical nutrition issues, e.g. hospital-based or one-to-one dietetic services.

- Policies related to general well-being, physical activity, tobacco or agriculture.

- An opinion piece, commentary, letter or book review.

was conducted to examine graphically the thematic changes over time. This enables readers to identify emerging, dominant, enduring and transient themes within a field of literature, and in the case of the present review, highlight the evolution of a field of research as new areas of inquiry are developed and gain traction over time ${ }^{(46)}$.

The ebb-and-flow analysis was created through a process of thematically coding articles to create a database that enumerated the number of articles published per year for each theme identified (that is, for example, obesity, childhood obesity, food security). This was transformed into a normalised data set (percentage of a theme's publications compared with the total volume of publications for a given time period; that is, for example, every year, 2 years, 5 years) and graphed in Microsoft Excel version 2010 using the ' $100 \%$ Stacked Area' chart function. A line graph representing the volume of publications per time period was overlain to provide additional context to the data. 


\section{Findings}

After the full-text review, sixty-three studies were selected for inclusion. The studies focused on a variety of countries, settings and nutrition policy issues. Most studies examined single cases of nutrition policy in one country although eleven studies included multiple country comparisons or data. The number of nutrition policy papers per annum increased over time, with a greater concentration occurring post 2007 (see Fig. 2).

The majority of papers had a geographical focus on the USA ( $n$ 31, $49 \%$ of all papers); this accounted for more than double the papers from the next most common geographical focus, Australia ( $n$ 12, 19\%). The remaining countries or regions represented included the UK, Japan, New Zealand, Canada, Norway, Finland and the European Union. A large number of papers ( $n$ 29, $46 \%$ ) focused their attention on national nutrition policy. State-focused nutrition policy, then local- and global-focused nutrition policy were the next most common (respectively: $n$ 14, $22 \% ; n 11,17 \% ; n 8,13 \%)$.

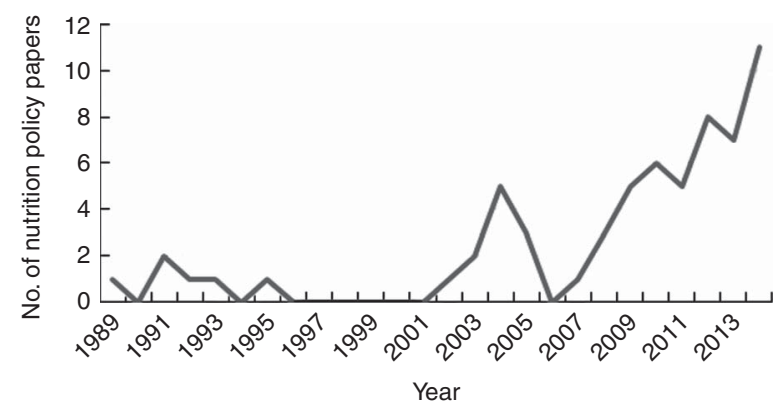

Fig. 2 Frequency of eligible nutrition policy articles (Jan 1986Dec 2015)
The topics covered in the nutrition policy papers were wide-ranging (see Fig. 3). Thirty-eight per cent of the papers focused on obesity, divided into general obesity ( $n$ 15, 24\%) and childhood obesity ( $n 9,14 \%$ ). Other more common topics were interest group influence ( $n 14,22 \%$ ), local government food policy $(n 6,9 \%)$ and the process of developing nutrition policy ( $n 6,9 \%$ ). The popularity of these topics has changed over time as can be seen in the ebb-and-flow analysis (Fig. 4). Earlier papers focused more on general policy content and implementation as well as school nutrition policy, whereas more recently there has been a stronger focus on obesity and the influence of interest groups in policy making. The ebb-and-flow analysis also illustrates the growing field of nutrition policy research and captures the fragmentation of the field as a wide variety of nutrition issues have become more salient over time.

\section{Use of political science policy process theories}

There has been an increase in the use of PPT in the reviewed nutrition policy papers in recent years (Fig. 5). However, this increase is fairly small with only $14 \%(n 9)$ of all the nutrition policy papers reviewed using empirically tested PPT. In 2014 there appeared to be a reversal of the slight upward trend, with none of the nutrition policy papers utilising PPT to analyse the described policy process.

While papers were reviewed for all empirically tested PPT, the only PPT utilised included Multiple Streams Theory (five papers) ${ }^{(47-51)}$, the Advocacy Coalition Framework (three papers) ${ }^{(9,52,53)}$ and one study used both Multiple Streams Theory and the Advocacy Coalition Framework $^{(54)}$. Five papers referred to PPT in their introduction or discussion but it was unclear whether they utilised theory in analysing their data ${ }^{(55-59)}$. Theory was used to retrospectively analyse a case study/studies in all but one of these papers. Gilson Sistrom ${ }^{(54)}$ utilised PPT

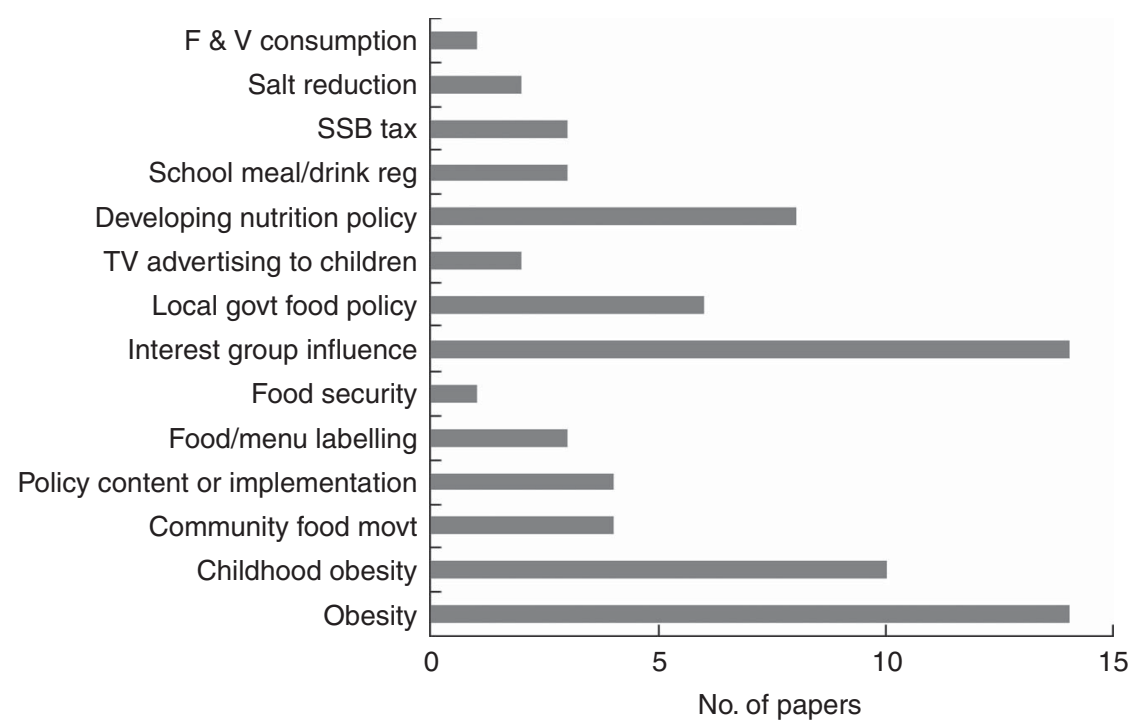

Fig. 3 Nutrition policy topics (F\&V, fruit and vegetables; SSB, sugar-sweetened beverages; reg, regulations; TV, television; govt, government; movt, movement) 


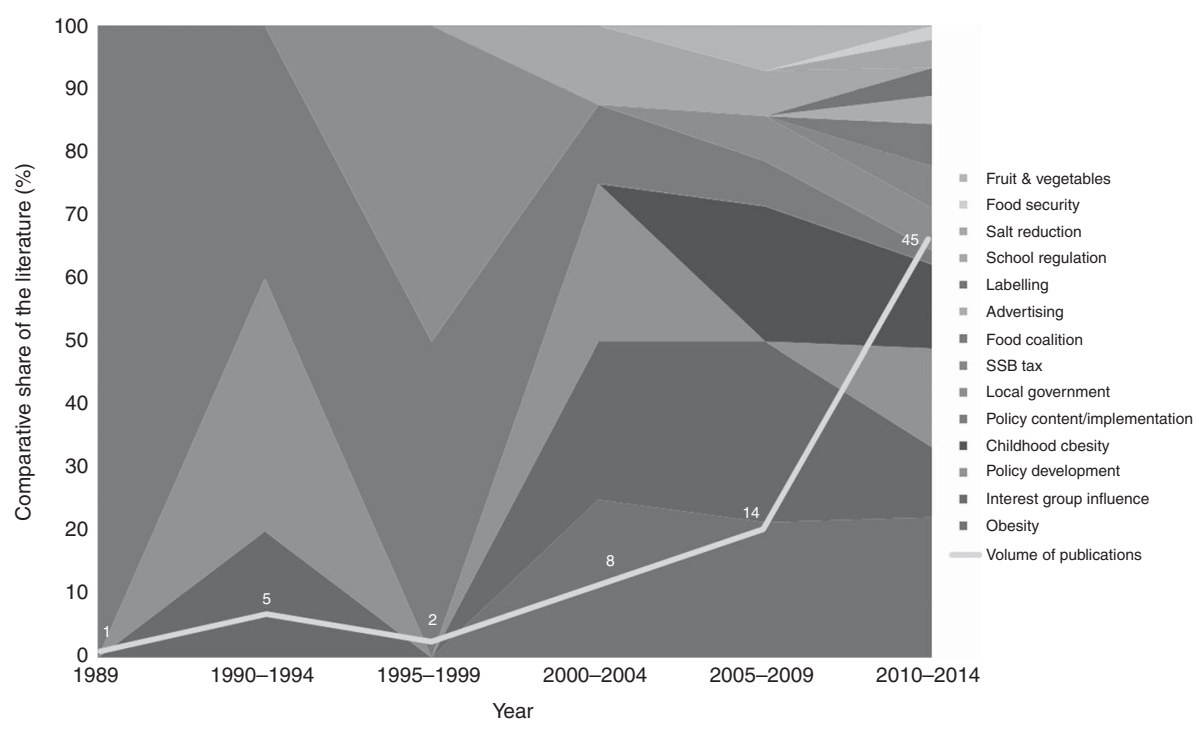

Fig. 4 Ebb-and-flow analysis of nutrition policy topics (SSB, sugar-sweetened beverages)

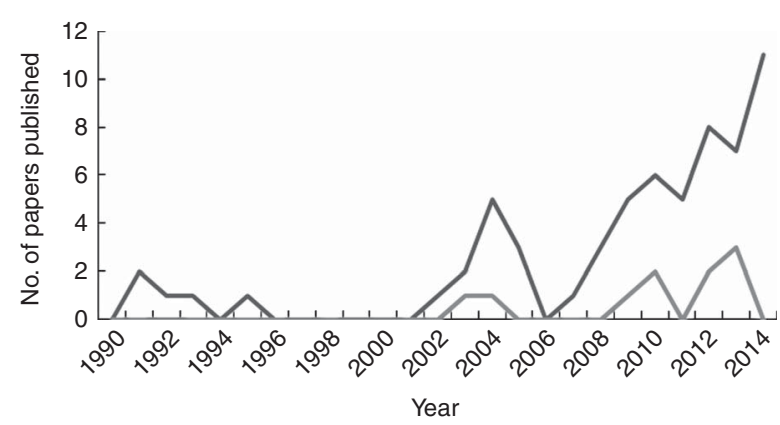

Fig. 5 Comparison of nutrition policy papers published (-) and those that use political science policy process theory $(\longrightarrow)$

prospectively, with the application of Multiple Streams Theory and the Advocacy Coalition Framework to guide advocacy around regulating 'junk food' in schools.

Seven papers (13\%) referred to theories other than PPT. The theories used included: Framing Theory ${ }^{(60)}$, which looks at one component of the policy process; and the Health Belief Model $^{(61)}$ and Stages of Change (Transtheoretical Model $)^{(10)}$, both of which are theories related to individual behaviour change rather than policy or system change. Three authors developed their own theories ${ }^{(62-64)}$ and one paper used Walt and Gilson's Health Policy Triangle which is a framework that identifies the elements and relationships of the policy process. This framework is a useful starting point for health policy analysts; however, the Health Policy Triangle does not explain or predict behaviour and outcomes as do the PPT referred to earlier ${ }^{(66)}$.

\section{Discussion}

The aim of the present review was to explore nutrition policy studies in high-income democratic countries and to examine whether political science PPT was being used to guide or analyse the described policy process. The review resulted in the inclusion of sixty-three papers although only nine (14\%) of these utilised PPT. This is a smaller percentage than the $18 \%$ found by Breton and De Leeuw in 2010 in their review of health promotion policy literature $^{(34)}$. This limited use of political science PPT may help explain the lack of progress in public health nutrition policy action. Understanding these theories can help policy advocates understand the complexities and identify the drivers and leverage points for influence in the policymaking process.

The publication of general nutrition policy papers and those utilising PPT has increased over time, with a greater concentration occurring post 2007, which is later than the increase post 1999 identified in the review of health promotion papers ${ }^{(34)}$. This may be due to nutrition professionals becoming more aware of political science theories because more are being published in the general health promotion literature. Further, this heightened awareness of PPT may have led to increased opportunities for collaboration or inter-sectoral approaches on nutrition issues with political scientists. However, another reason is that there are increasingly more publishing options available for health policy papers. Fifty eight per cent of the journals cited for the current review were not in existence in 1986 and $30 \%$ of the journals only came into being post 2000.

The ebb-and-flow analysis demonstrated the change in topics in nutrition policy papers over time. Earlier papers focused more on general policy content and implementation as well as school nutrition policy, whereas more recently there has been a strong focus on obesity. Of note is the literature gap between 1996 and 2001. The gap indicates a possible lack of research in this period. However, as the total numbers of policy papers being 
produced at the time were so low (e.g. one or two per year), it is not unreasonable to assume that those early years did not produce any nutrition policy papers. In more recent years, new policy topics emerged which have expanded the field of literature, but obesity continues to rise to prominence. This result is to be expected due to the worldwide trend and concern about increasing obesity prevalence ${ }^{(1,5,8)}$. The more recent diversification of topics seems to be following the advent of state-based legislation in different countries encouraging the exploration of specific themes and salient debates.

A progression from focusing mostly on the content or implementation of nutrition policy to a greater focus on the policy-making process itself has been evident within the present review. This is positive progress as earlier criticisms of public health policy research were that the focus was predominantly on policy content and evaluating policy impact and outcomes, paying little attention to the policy-making process ${ }^{(26)}$. However, in line with the review of low- and middle-income country healthy policy literature conducted by Gilson and Raphaely ${ }^{(36)}$, most of the analyses of nutrition policy were relatively intuitive and assumptions on which the analyses were based were seldom identified. The majority of articles provided descriptions of the policy-making process or described suggested barriers and facilitators to policy making as gleaned by policy makers. Most papers in the present review relied on anecdotes to explain what had occurred in the policy process or ignored the process totally. Very few papers explained how the policy change happened (or did not happen). This may be due to the authors' lack of awareness around the complexity of the policy-making process and where theories could help identify the discourse of the different vested interests, as well as system-wide events that could potentially shift the balance in favour of one actor over another ${ }^{(66)}$.

Another notable deficit is the lack of analysis around power. Power is not simply about visible conflicts whereby one group wins and another loses; it can also involve exercising power to reinforce social attitudes ${ }^{(67)}$. If the weight of public opinion is against government action, governments may not intervene. Interest groups are also able to exercise power in keeping an issue off the government agenda. This may occur by using their power to keep 'safe' issues on the agenda to take up the attention of policy makers ${ }^{(67)}$. In the current review power is broadly discussed in a range of articles, with some providing a description of influence strategies used by vested interests to keep healthy food policies off the agenda. However, very few articles explicitly explored the role of power in policy making. Two papers that did provide an exploration of power in the policy-making process were the paper by Field and Gauld ${ }^{(68)}$ which does not use a theory or framework to analyse power but instead uses the vested interest construct to explore how three different interest groups influenced policy around marketing to children in New Zealand. Also, the paper by Hobbs et al. ${ }^{(52)}$ utilised an adaption of the Advocacy Coalition Framework to analyse the policy-making process around federal school meals regulations by examining the actions of different interest groups, their goals, resource base and strategies for influence.

The majority of papers using PPT emerged from the USA. There is a long history of policy advocacy and some success in nutrition policy action in the USA particularly at a state level. However, Scandinavian countries have also been active in achieving nutrition policy action ${ }^{(69)}$, yet they have published comparatively little, with no studies found using PPT. This may be because they are publishing in non-English-language journals or because lobbying is heavily embedded in the system of government in USA and therefore interest groups are potentially more advanced in political lobbying. One other reason may be that the USA has more pressure for academics to publish due to its public university ratings system which has been active since the late $1980 \mathrm{~s}^{(70)}$.

A large number of the nutrition papers reviewed (47\%) focused their attention on national nutrition policy. This may be representative of the traditional view of government as having a directive, stewardship-like role in managing public health. Although, for many of the countries represented in the current review, the national level of government is responsible for legislative or regulatory functions typically associated with public health reform and so a focus on this level of government is to be expected.

PPT was used to retrospectively analyse a case study/ studies in all but one of the papers that used PPT. There seems to be a missed opportunity in utilising these theories prospectively to develop and inform policy advocacy strategies. However, before practitioners and researchers can use these theories to develop and inform policy advocacy strategies, they need to understand and be able to apply them. Typically PPT are not covered in university training for public health professionals, let alone those who specialise in nutrition. Including training around these theories and the policy-making process in the curriculum would assist in developing the core competency of advocacy for the next generation of public health nutritionists. To better equip current nutrition professionals for future policy advocacy work, better training and a stronger research focus on nutrition policy processes are required.

\section{Limitations}

The present review is subject to several limitations. It is possible that relevant articles were not included in the review given the restrictions in the search terms and that only English-language literature was considered. In addition, although known to exist, relevant book chapters, doctoral theses and grey literature were excluded from analysis. We have accepted this limitation because, without peer review, it is not possible to verify the quality 
of the study, although we acknowledge that there is more to be learnt from the grey literature. On both grounds, therefore, the review cannot claim to be a comprehensive survey of all available nutrition policy work in highincome, democratic countries conducted between 1986 and 2014. Despite these limitations, the review contributes to improved recognition of the political dimension of nutrition policy making and can continue to stimulate critical thinking about current and future policy making.

\section{Conclusion}

The politics of agenda setting, policy formulation and implementation are complex, with conflict and power being intrinsic elements. PPT can help a broad range of health practitioners, including public health nutrition researchers and practitioners, understand these complexities and identify leverage points for influence. Oliver ${ }^{(71)}$ states that researchers and health professionals who understand the political dimensions of health policy 'can conduct more realistic research and evaluation, better anticipate opportunities and constraints on governmental action and design more effective policies and programs'. While it is heartening to see a small increase over time in the use of PPT when analysing nutrition policy, this has been limited and wider use needs to be encouraged. More practical measures could be taken to ensure those trying to influence or understand the nutrition policy-making process are equipped with basic knowledge around these theories, which will enable them to become better advocates for policy change.

\section{Acknowledgements}

Acknowledgements: The authors wish to acknowledge the guidance provided by Leonie Ruddick-Collins, Elena Jansen, Jennifer Browne and Kamila Davidson in preparation of the manuscript. Financial support: This research received no specific grant from any funding agency in the public, commercial or not-for-profit sectors. K.C. is supported by an Australian National Health and Medical Research Council (NHMRC) Postgraduate Scholarship. Conflict of interest: None. Authorship: K.C. searched and reviewed the literature and drafted the manuscript. D.G. assisted in reviewing the literature. T.D. created the ebb-and-flow diagram. A.L., T.D. and D.G. offered valuable input and feedback on the manuscript. Ethics of human subject participation: Not applicable.

\section{References}

1. Institute for Health Metrics and Evaluation (2013) The State of US Health: Innovations, Insights, and Recommendations from the Global Burden of Disease Study. Seattle, WA: IHME.
2. National Health and Medical Research Council (2013) Dietary Guidelines for Australians. Canberra: Australian Governement Printing Service.

3. Lytle LA \& Fulkerson JA (2002) Assessing the dietary environment: examples from school-based nutrition interventions. Public Health Nutr 5, 893-899.

4. Raine KD (2010) Addressing poor nutrition to promote heart health: moving upstream. Can J Cardiol 26, Suppl. C, 21C-24C.

5. Roberto CA, Swinburn B, Hawkes C et al. (2015) Patchy progress on obesity prevention: emerging examples, entrenched barriers, and new thinking. Lancet 385, 2400-2409.

6. Sacks G, Veerman J, Moodie M et al. (2010) 'Traffic-light' nutrition labelling and 'junk-food' tax: a modelled comparison of cost-effectiveness for obesity prevention. Int J Obes (Lond) 35, 1001-1009.

7. Cobiac LJ, Veerman L \& Vos T (2013) The role of costeffectiveness analysis in developing nutrition policy. Annu Rev Nutr 33, 373-393.

8. World Health Organization (2003) Diet, Nutrition and the Prevention of Chronic Diseases. Joint WHO/FAO Expert Consultation. WHO Technical Report Series no. 916. Geneva: WHO.

9. Johnson DB, Cheadle A, Podrabsky M et al. (2013) Advancing nutrition and obesity policy through cross-sector collaboration: the Local Farms - Healthy Kids Initiative in Washington State. J Hunger Environ Nutr 8, 171-186.

10. Swinburn B \& Wood A (2013) Progress on obesity prevention over 20 years in Australia and New Zealand. Obes Rev 14, Suppl. 2, 60-68.

11. Clavier C \& De Leeuw E (2013) Health Promotion and the Policy Process. Oxford: Oxford University Press.

12. Palmer G \& Short S (2000) Health Care and Public Policy: An Australian Analysis, 3rd ed. South Melbourne, VIC: Macmillan Publishers.

13. Bridgman P \& Davis G (2004) The Australian Policy Handbook, 3rd ed. Crow's Nest, NSW: Allen \& Unwin.

14. Vogel L (2010) Public health and nutrition advocates fear regulatory inaction has become the norm. CMAJ 182, E465-E466.

15. Corvalán C, Reyes M, Garmendia ML et al. (2013) Structural responses to the obesity and non-communicable diseases epidemic: the Chilean Law of Food Labeling and Advertising. Obes Rev 14, Suppl. 2, 79-87.

16. Ham C \& Hill M (1984) The Policy Process in the Modern Capitalist State. Brighton: Harvester Wheatsheaf.

17. Dahl R (1957) The concept of power. Behav Sci 2, 201-215.

18. Lasswell H \& Kaplan A (1950) Power and Society. A Framework for Political Inquiry. New Haven, CT: Yale University Press.

19. Altensetter C (1987) The Political, Economic and Institutional Prerequisites of Legislation and Planning in Support of Health Promotion. Copenhagen: WHO.

20. Lewis JM (2006) Being around and knowing the players: networks of influence in health policy. Soc Sci Med $\mathbf{6 2}$, 2125-2136.

21. Onyx J, Dalton B, Melville R et al. (2008) Implications of government funding of advocacy for third-sector independence and exploration of alternative advocacy funding models. Aust J Soc Issues 43, 631-648.

22. Hughes R (2008) Workforce development: challenges for practice, professionalism and progress. Public Health Nutr 11, 765-767.

23. Hughes R (2003) Public health nutrition workforce composition, core functions, competencies and capacity: perspectives of advanced-level practitioners in Australia. Public Health Nutr 6, 607-613.

24. Walt G \& Gilson L (1994) Reforming the health sector in developing countries: the central role of policy analysis. Health Policy Plan 9, 353-370. 
25. Bambra C (2009) Changing the world? Reflections on the interface between social science, epidemiology and public health. J Epidemiol Community Health 63, 867-868.

26. Bernier NF \& Clavier C (2011) Public health policy research: making the case for a political science approach. Health Promot Int 26, 109-116.

27. Bryant T (2002) Role of knowledge in public health and health promotion policy change. Health Promot Int 17, 89-98.

28. Sabatier PA (1991) Toward better theories of the policy process. PS: Polit Sci Politics 24, 147-156.

29. Lapping K, Frongillo EA, Studdert LJ et al. (2012) Prospective analysis of the development of the national nutrition agenda in Vietnam from 2006 to 2008. Health Policy Plan 27, 32-41.

30. Blanchet NJ \& Fox AM (2013) Prospective political analysis for policy design: enhancing the political viability of singlepayer health reform in Vermont. Health Policy 111, 78-85.

31. Jenkins-Smith HC \& Sabatier PA (1994) Evaluating the advocacy coalition framework. J Public Policy 14, 175-203.

32. Baumgartner FR \& Jones BD (1993) Agendas and Instability in American Politics. Chicago, IL: University of Chicago Press.

33. Kingdon JW (1984) Agendas, Alternatives, and Public Policies. New York: Harper Collins.

34. Breton E \& De Leeuw E (2011) Theories of the policy process in health promotion research: a review. Health Promot Int 26, 82-90.

35. Smith KE \& Katikireddi SV (2013) A glossary of theories for understanding policymaking. I Epidemiol Community Health 67, 198-202.

36. Gilson L \& Raphaely N (2008) The terrain of health policy analysis in low and middle income countries: a review of published literature 1994-2007. Health Policy Plan 23, 294-307.

37. Macintyre S (2012) Evidence in the development of health policy. Public Health 126, 217-219.

38. Catford J (2006) Creating political will: moving from the science to the art of health promotion. Health Promot Int 21, 1-4.

39. Drewnowski A \& Darmon N (2005) Food choices and diet costs: an economic analysis. J Nutr 135, 900-904.

40. Contento IR, Williams SS, Michela JL et al. (2006) Understanding the food choice process of adolescents in the context of family and friends. J Adolesc Health 38, 575-582.

41. Crammond B, Van C, Allender S et al. (2013) The possibility of regulating for obesity prevention - understanding regulation in the Commonwealth Government. Obes Rev 14, 213-221.

42. Burns C, Bentley R, Thornton L et al. (2015) Associations between the purchase of healthy and fast foods and restrictions to food access: a cross-sectional study in Melbourne, Australia. Public Health Nutr 18, 143-150.

43. Story M, Kaphingst KM, Robinson-O'Brien R et al. (2008) Creating healthy food and eating environments: policy and environmental approaches. Annu Rev Public Health 29, 253-272.

44. World Health Organization (1986) The Ottawa Charter for Health Promotion. Geneva: WHO; available at http://www. who.int/healthpromotion/conferences/previous/ottawa/en/ index.html

45. The Economist Intelligence Unit (2014) Democracy Index 2014: Democracy and Its Discontents. UK: The Economist Intelligence Unit.

46. Havre S, Hetzler E, Whitney P et al. (2002) ThemeRiver: visualizing thematic changes in large document collections. IEEE Trans Visual Comput Graph 8, 9-20.

47. Caraher M, Carey R, Mcconell K et al. (2013) Food policy development in the Australian State of Victoria: a case study of the Food Alliance. Int Plan Stud 18, 78-95.

48. Craig RL, Felix HC, Walker JF et al. (2010) Public health professionals as policy entrepreneurs: Arkansas's childhood obesity policy experience. Am J Public Health 100, 2047-2052.
49. Lyn R, Aytur S, Davis TA et al. (2013) Policy, systems, and environmental approaches for obesity prevention: a framework to inform local and state action.J Public Health Manag Pract 19, 3 Suppl. 1, S23-S33.

50. Mosier SL (2013) Cookies, candy, and coke: examining state sugar-sweetened-beverage tax policy from a multiple streams approach. Int Rev Public Admin 18, 93-120.

51. Yeatman HR (2003) Food and nutrition policy at the local level: key factors that influence the policy development process. Crit Public Health 13, 125-138.

52. Hobbs SH, Ricketts TC, Dodds JM et al. (2004) Analysis of interest group influence on federal school meals regulations 1992 to 1996. J Nutr Educ Behav 36, 90-98.

53. Johnson DB, Payne EC, Mcneese MA et al. (2012) Menulabeling policy in King County, Washington. Am J Prev Med 43, 3 Suppl. 2, S130-S135.

54. Gilson Sistrom M (2010) Oregon's Senate Bill 560: practical policy lessons for nurse advocates. Policy Polit Nurs Pract 11, 29-35.

55. Allender S, Gleeson E, Crammond B et al. (2012) Policy change to create supportive environments for physical activity and healthy eating: which options are the most realistic for local government? Health Promot Int 27, 261-274.

56. Shill J, Mavoa H, Allender S et al. (2012) Government regulation to promote healthy food environments - a view from inside state governments. Obes Rev 13, 162-173.

57. Kersh R (2009) The politics of obesity: a current assessment and look ahead. Milbank $Q$ 87, 295-316.

58. Gollust SE, Kite HA, Benning SJ et al. (2014) Use of research evidence in state policymaking for childhood obesity prevention in Minnesota. Am J Public Health 104, 1894-1900.

59. Dodson EA, Fleming C, Boehmer TK et al. (2009) Preventing childhood obesity through state policy: qualitative assessment of enablers and barriers. J Public Health Policy 30, Suppl. 1, S161-S176.

60. Shelley JJ (2012) Addressing the policy cacophony does not require more evidence: an argument for reframing obesity as caloric overconsumption. BMC Public Health 12, 1042.

61. Freudenberg N (2005) Public health advocacy to change corporate practices: implications for health education practice and research. Health Educ Behav 32, 298-319.

62. Field P, Gauld R \& Lawrence M (2012) Evidence-informed health policy - the crucial role of advocacy. Int J Clin Pract 66, 337-341.

63. Freudenberg N, Bradley SP \& Serrano M (2009) Public health campaigns to change industry practices that damage health: an analysis of 12 case studies. Health Educ Behav 36, 230-249.

64. Miller D \& Harkins C (2010) Corporate strategy, corporate capture: food and alcohol industry lobbying and public health. Crit Soc Policy 30, 564-589.

65. Walt G, Shiffman J, Schneider H et al. (2008) 'Doing' health policy analysis: methodological and conceptual reflections and challenges. Health Policy Plan 23, 308-317.

66. Breton E, Richard L, Gagnon F et al. (2013) Coalition advocacy action and research for policy development. In Health Promotion and the Policy Process, pp. 43-62 [C Clavier and E de Leeuw, editors]. Oxford: Oxford University Press.

67. Cairney P (2012) Understanding Public Policy: Theories and Issues. Basingstoke: Palgrave Macmillan.

68. Field P \& Gauld R (2011) How do vested interests maintain outdated policy? The case of food marketing to New Zealand children. Open Health Serv Policy J 4, 30-38.

69. Lloyd-Williams F, Bromley H, Orton L et al. (2014) Smorgasbord or symphony? Assessing public health nutrition policies across 30 European countries using a novel framework. BMC Public Health 14, 1195.

70. Starbuck WH (2013) Why and where do academics publish? M@n@gement16,707-718.

71. Oliver TR (2006) The politics of public health policy. Annu Rev Public Health 27, 195-233. 